\title{
Optimization and characterization of gelatin and chitosan extracted from fish and shrimp waste
}

\author{
AIT BOULAHSEN $M^{1 *}$, CHAIRI $H^{1}$, LAGLAOUI $A^{2}$, ARAKRAK $A^{2}$, ZANTAR $S^{3}$, \\ BAKKALI $M^{2}$, HASSANI $M^{1}$ \\ 1. Department of Biology, Polydisciplinary Faculty of Larache, ABDELMALEK ESSAADI \\ University, Tangier, Morocco \\ 2. Department of Biology, Faculty of Science and Technology, ABDELMALEK ESSAADI \\ University, Tangier, Morocco \\ 3. National Institute of Agricultural Research, Tangier, Morocco
}

\begin{abstract}
Fish and seafood processing industries generate large quantities of waste which are at the origin of several environmental, economic and social problems. However fish waste could contain high value-added substances such as biopolymers. This work focuses on optimizing the gelatin and chitosan extraction from tilapia fish skins and shrimp shells respectively. The gelatin extraction process was optimized using alkali acid treatment prior to thermal hydrolysis. Three different acids were tested at different concentrations. Chitosan was obtained after acid demineralization followed by simultaneous hydrothermal deproteinization and deacetylation by an alkali treatment with different concentrations of $\mathrm{HCl}$ and $\mathrm{NaOH}$. The extracted gelatin and chitosan with the highest yield were characterized by determining their main physicochemical properties (Degree of deacetylation, viscosity, $\mathrm{pH}$, moisture and ash content). Results show a significant influence of the acid type and concentration on the extraction yield of gelatin and chitosan, with an average yield of $12.24 \%$ and $3.85 \%$ respectively. Furthermore, the obtained physicochemical properties of both extracted gelatin and chitosan were within the recommended standard values of the commercial ones used in the industry.
\end{abstract}

Key words: Waste, extraction, characterization, chitosan, gelatin

Corresponding author: maitboulahsen@uae.ac.ma 


\section{Introduction}

Fish and seafood processing industries occupy a strategic place in the Moroccan economy. They ensure $50 \%$ of the country's agri-food exports for a value of 14 billion dirhams. Among several activities, there are about 20 shrimp shelling and semi-preserved smoked fish companies processing more than 20000 tons of fish [1]. They generate more than 14 000 tons of waste that are thrown directly into landfills causing a serious environmental problems.

However, these wastes are composed of skins and shells that may contain high valueadded substances. Extraction of biopolymers like gelatin and chitosan is one of the most important ways for waste valorization. Gelatin, a polypeptide extracted from fish skins, offers various functional properties such as film-forming, gelling and emulsifying properties and can be applied in several fields like food, pharmaceutical and cosmetic industry [2].On the other hand, chitosan, a polysaccharide derived from chitin can be extracted from crustaceans shells, especially shrimps, is widely studied for its excellent functional and biological properties, and has various applications in several fields such as wastewater treatment, food, pharmaceutical, textile and cosmetic industry [3].Therefore, the valorization of these by-products can represent an important eco-friendly alternative that allow, in addition to reducing the environmental impact, the enhancement of creativity, competitiveness and productivity of companies. Despite that extraction and characterization of these two biopolymers have been already studied by several authors all over the world [4-6], to the best of our knowledge, studies at national level are inexistent. Moreover, data obtained from other authors cannot be extrapolated due to the specificity and characteristics of each raw material. Thus, the main objective of this work is to optimize the extraction and characterization of gelatin and chitosan from tilapia skins (aquaculture fish) and shrimp shells generated by agribusiness units in the northern region of Morocco.

\section{Material and methods}

\subsection{Raw material and chemical reagents}

Shrimp waste and tilapia skins have been used as a source of chitosan and gelatin extraction respectively. They have been provided by two companies, located in the north of Morocco. All the chemicals reagents used were of analytical grade.

\subsection{Chitosan extraction}

Chitosan was obtained after the two following steps: acid demineralization followed by simultaneous deproteinization and deacetylation by hydrothermal-chemical method in an alkali environment, with a solid-liquid ratio of 1:10 w/v (weight of dry shell / volume of diluted solution), according to the method described by Truong et al. (2007) [7] with some modifications.

Shrimp shells was first pretreated prior to their use, washed with excess water to remove organic residues (tissues), and then dried for 48 hours. Once dried, they were reduced to powder using a mixer in order to have particles with a uniform granulometry of less than $0.5 \mathrm{~mm}$.

Demineralization step: $20 \mathrm{~g}$ of dried powder of shrimp shells were added to $\mathrm{HCl}$ solution $(1 / 10 \mathrm{w} / \mathrm{v})$ at 3 different concentrations $(0.5 \mathrm{M}, 2 \mathrm{M}$ and $3.5 \mathrm{M})$, the solutions were stirred for $150 \mathrm{~min}$ at $50^{\circ} \mathrm{C}$, then washed with distilled water until a neutral $\mathrm{pH}$ of 7 was obtained.

Deproteinization and deacetylation steps: These two steps were performed simultaneously in an alkali environment. The product obtained from the previous step was 
added to $\mathrm{NaOH}$ solution at 2 different concentrations $(7.5$ and $10 \mathrm{M})$ for $120 \mathrm{~min}$ at $100^{\circ} \mathrm{C}$. The resulted product was then filtered and washed several times with distilled water. At about neutral $\mathrm{pH}$, the substrate was dried in an oven at $80^{\circ} \mathrm{C}$ for 24 hours.

\subsection{Gelatin extraction}

The extraction method of gelatin was carried out as described by Niu et al. (2013) [8]. First, the tilapia skins $(30 \mathrm{~g})$ were soaked in water $(1: 6 \mathrm{w} / \mathrm{v})$ for $10 \mathrm{~min}$, drained into a filter cloth and then washed twice to remove the residues. The washing step consists of stirring the mixture for 4 minutes at $180 \mathrm{rpm}$ and then draining the skins in a filter cloth. After washing, the excess water was removed, and then the skins were immersed in $0.3 \mathrm{M} \mathrm{NaOH}$ solution (1: $6 \mathrm{w} / \mathrm{v})$ for $1 \mathrm{~h}$. Then, the skins were drained for 5 minutes, washed five times and dipped in 3 different acid solutions with 2 different concentrations: $\mathrm{HCl}$ at $(0.05$ and $0.07 \mathrm{M})$, acetic acid at $(0.18$ and $0.20 \mathrm{M})$ and citric acid at $(0.03$ and $0.05 \mathrm{M})$ for $1 \mathrm{~h}$. The skins were drained and washed five times as described above. After the acid treatment, they were soaked in distilled water $(1: 4 \mathrm{w} / \mathrm{v})$ at $50^{\circ} \mathrm{C}$ in a water bath for $3 \mathrm{~h}$ and then filtered to recover the gelatin-containing solution. The solution was dried in an oven until a constant weight was obtained.

\subsection{Extraction Yield}

The extraction yield of gelatin and chitosan was calculated according to the following formula:

$$
\text { Extraction Yield }(\%)=(\text { dry weight after extraction }(g) / \text { weight of raw material }(g)) * 100
$$

\subsection{Physicochemical characteristics}

Physicochemical properties of extracted gelatin and chitosan with the highest yield were determined. Moisture content (\%), ash content (\%), and $\mathrm{pH}$ were measured according to AOAC official methods (2000) [9]. The viscosity of gelatin solution was determined with a falling ball viscometer; a $6.67 \%$ (w/v) gelatin solution was obtained by dissolving gelatin in $45 \mathrm{~mL}$ of distilled water and maintained at $60^{\circ} \mathrm{C}$ for 30 minutes, after that, the gelatin solution was poured into the measuring tube, then the Ball (diameter $=15.60 \mathrm{~mm}, \rho=2.235$ $\mathrm{g} / \mathrm{cm}^{3}$ ) was placed into the tube, the falling time (s) of the ball moving from the Upper ring to the lower ring of the tube was determined by using a stopwatch, the dynamic viscosity $n$ (in $\mathrm{mPa}^{*} \mathrm{~s}$ ) was calculated using the following equation:

$$
\eta=K^{*}\left(\rho_{1}-\rho_{2}\right) * t
$$

Where, $\mathbf{K}=$ ball constant $\mathrm{mPa} * \mathrm{~s}^{*} \mathrm{~cm}^{3} / \mathrm{g} * \mathrm{~s}, \boldsymbol{\rho}_{\mathbf{1}}=$ density of the Ball in $\mathrm{g} / \mathrm{cm}^{3}, \boldsymbol{\rho}_{\mathbf{2}}=$ density of the sample $\mathrm{g} / \mathrm{cm}^{3}$, and $\mathbf{t}=$ falling time of the ball in seconds.

The degree of deacetylation (DD) of chitosan was determined by potentiometric titration as described by Dima et al. (2017) [10] with a slight modifications; a solution of $100 \mathrm{mg}$ of chitosan, $3 \mathrm{~mL}$ of $0.3 \mathrm{M} \mathrm{HCl}$ and $40 \mathrm{~mL}$ of distilled water were prepared and stirred overnight, then the solution was titrated with $\mathrm{NaOH} 0.1 \mathrm{M}, \mathrm{pH}$ meter was used for $\mathrm{pH}$ measurements under continuous stirring, The titrant was added until the $\mathrm{pH}$ value reached 4.5, the volume of $\mathrm{NaOH}$ was recorded as $\mathrm{V} 1, \mathrm{NaOH}$ was then added until a $\mathrm{pH}$ of 8.5 was obtained and the added volume was recorded as V2. The DD was obtained by the following equation:

$$
D D(\%)=203 M_{e q} /\left(1+42 M_{e q}\right)
$$


Where, $\mathbf{M}_{\mathrm{eq}}=\left(\mathrm{N}^{*} \Delta \mathrm{V}\right) / \mathrm{w}, \Delta \mathrm{V}=\mathrm{V} 2-\mathrm{V} 1=$ volume added in $\mathrm{mL}$ of $\mathrm{NaOH}$ between $\mathrm{pH} 4.5$ and $\mathrm{pH}$ 8.5., $\mathrm{N}=$ normality of $\mathrm{NaOH}$ Solution, $\mathrm{w}=$ dry weight of chitosan in the test sample, in $\mathrm{mg}, \mathbf{2 0 3}$ is the molar mass of glucosamine and $\mathbf{4 2}$ is the molar mass of the acetyl group.

\subsection{Statistical analysis}

All measurements were done in triplicate. Data analysis was carried out by ANOVA using IBM SPSS STATISTICS 20. Differences between pairs of means were evaluated on the basis of $95 \%$ confidence intervals. The level of significance was $\mathrm{p} \leq 0.05$.

\section{Results and discussions}

\subsection{Yield of chitosan}

Figure 1 shows the effect of $\mathrm{NaOH}(7.5,10 \mathrm{M})$ and $\mathrm{HCl}(0.5,2,3.5 \mathrm{M})$ concentrations on the chitosan yield extraction. The yield varies between $2.1 \%$ and $4.4 \%$ for all treatments. The highest yield $(4.4 \%)$ was obtained by a demineralization using $0.5 \mathrm{M}$ $\mathrm{HCl}$, followed by a simultaneous deproteinization and deacetylation with 7.5 M NaOH. Acid concentration has a significant effect $(\mathrm{p} \leq 0.05)$ on the yield extraction, in fact, the yield decreased as the acid concentration increased. It can be explained by an extensive demineralization step with higher acid concentrations, that causes an important loss in the weight of the final product [11]. No significant influence of the $\mathrm{NaOH}$ concentration on the yield extraction has been shown $(\mathrm{p} \geq 0.05$ ). Our results are similar to those obtained by Ahing et al. (2016) [12] and slightly lower than those obtained by Nouri et al. [4]. Differences in yield extraction can be due to the difference of the extraction conditions, precisely, time and temperature of deacetylation [6].

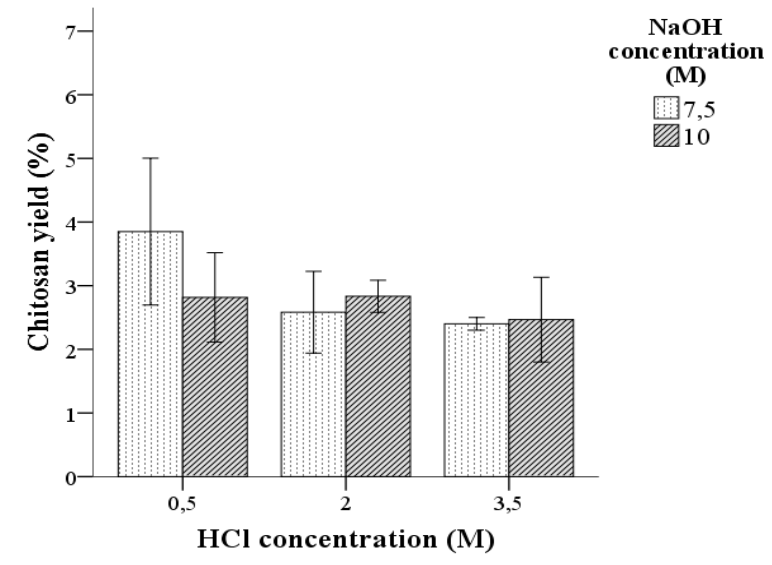

Fig.1. Effect of $\mathrm{NaOH}$ and $\mathrm{HCl}$ concentration on chitosan yield. Bars represent the standard deviation $(n=3)$

\subsection{Physicochemical characteristics of extracted chitosan}

Table 1 represents the main physicochemical characteristics obtained for the extracted chitosan with the highest yield. The degree of deacetylation (DD\%), described as the crucial factor determining the physicochemical behavior and biological functionality of chitosan [13], reached a value of $67.03 \%$. Our results are similar to those obtained by Tokatlı et al. (2017) [14], but higher than those presented by Kumari et al. (2015) [15], and lower than those obtained by Sagheer et al. (2009) [16]. These variations may be affected by the different nature of raw material and the parameters of deacetylation process (time and temperature). Truong et al. (2007) [7] and Kumar (2000) [17] reported that the DD\% 
necessary to obtain a chitosan product is $65 \%$ or higher. Ash content indicates the effectiveness of the demineralization step, No et al. (1995) [18] reported that chitosan of a good quality must have less than $1 \%$ of ash content, which is in agreement with the results obtained in this study $(0.94 \%)$. Moisture content, on the other hand, reached an average percentage of 8.71, similar to the results obtained by Lertsutthiwong et al. (2002) [19] who showed that moisture content varies from 6 to $12 \%$ depending on the different chemical treatments, Alishahi et al. (2011) [20] also suggested that a suitable chitosan must contain lower than $10 \%$ of moisture content.

Table 1. Physicochemical characteristics of extracted chitosan

\begin{tabular}{ccccc}
\hline & Yield (\%) & $\begin{array}{c}\text { Moisture } \\
\text { content (\%) }\end{array}$ & $\begin{array}{c}\text { Ash } \\
\text { content } \\
(\boldsymbol{\%})\end{array}$ & $\begin{array}{c}\text { Degree of } \\
\text { desacetylation } \\
(\boldsymbol{\%})\end{array}$ \\
\hline $\begin{array}{c}\text { Chitosan } \\
\text { (HCl 0.5 M, } \\
\text { NaOH 7.5 } \\
\text { M) }\end{array}$ & $3,85 \pm 0,576$ & $8,71 \pm 0,412$ & $0,94 \pm 0,026$ & $67,03 \pm 1,743$ \\
\hline
\end{tabular}

\footnotetext{
*Values were means \pm standard deviation from triplicate determinations.
}

\subsection{Yield of gelatin}

Figure 2 shows the effect of different acid treatments $\mathrm{HCl}(0.03$ and $0.05 \mathrm{M})$, acetic acid $(0.07$ and $0.18 \mathrm{M})$ and citric acid $(0.05$ and $0.20 \mathrm{M})$ on the gelatin yield extraction. Results show that the yield varies between $6.26 \%$ and $13.16 \%$, depending on the type and acid concentration used. Average yield was $10.53 \%, 11.55 \%$ and $7.55 \%$ for $\mathrm{HCl}$, acetic acid and citric acid respectively. Our results are higher than those obtained by Jamilah and Harvinder (2002) [21] (7.81\%) and in agreement with those reported by Jamilah et al. (2011) [5] (12.92\%). Acid treatments eliminate certain proteins and other undesirable components, disrupts collagen molecule linkages and allows the skin to swell, which is effective for gelatin extraction [22]. In terms of the influence of acid concentration on the yield, Niu et al. (2013) [8] reported that the acid concentration should be high enough for optimal extraction, but should not be used in excess, to avoid over-hydrolysis of the collagen molecules and in consequence losses in yield. Our results show that the yield increases as the acid concentration increases for all the acid treatments, yet with no significant influence $(\mathrm{p} \geq 0.05)$ on the extraction yield, which is in agreement with the results obtained by Zeng et al. (2010) [23] 


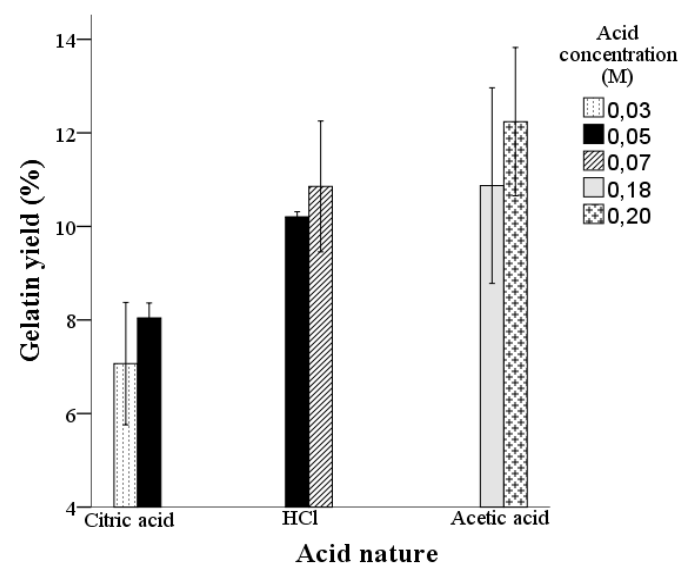

Fig.2. Effect of acid treatment on gelatin yield. Bars represent the standard deviation $(\mathrm{n}=3)$

\subsection{Physicochemical characteristics of extracted gelatin}

The extracted gelatin with the highest yield $(0.20 \mathrm{M}$ acetic acid treatment), was characterized, to determine its main physicochemical properties as presented in table 2. $\mathrm{pH}$ obtained was 5.62, which is similar to the results obtained by Jamilah et al. (2011) [5] for red tilapia, however $\mathrm{pH}$ values obtained by Choi et al. (2000) [24] ranged from 4.2 to 6.5 , Alfaro et al. (2015) [25] reported that the variation of $\mathrm{pH}$ values is due mostly to the extraction process, they also reported that $\mathrm{pH}$ value affect directly the viscosity of gelatin. In our case, the viscosity obtained was $5.19 \mathrm{mPa} * \mathrm{~s}$ at $60^{\circ} \mathrm{C}$, which is within the range of the values for commercial gelatins [26]. The values obtained for moisture and ash content were $8.51 \%$ and $0.67 \%$ respectively, which are in agreement with the results obtained by Jamilah et al. (2011) [5] and Zeng et al. (2010) [23], and within the standard values of commercial gelatins, reported by Alfaro et al. (2015) [25]: $2.6 \%$ as maximum ash content, and less than $14 \%$ for the moisture content.

Table 2.Physicochemical characteristics of extracted gelatin

\begin{tabular}{|c|c|c|c|c|c|}
\hline & Yield $(\%)$ & $\begin{array}{c}\text { Moisture } \\
\text { content } \\
(\%)\end{array}$ & $\begin{array}{c}\text { Ash } \\
\text { content } \\
(\%)\end{array}$ & $\begin{array}{l}\text { Viscosity } \\
(\mathbf{m P a} * \mathbf{s})\end{array}$ & pH \\
\hline $\begin{array}{c}\text { Gelatin } \\
(0.20 \mathrm{M} \\
\text { acetic } \\
\text { acid })\end{array}$ & $12.24 \pm 0.888$ & $8.51 \pm 0.122$ & $0.67 \pm 0.090$ & $5.19 \pm 0.025$ & $5.62 \pm 0.091$ \\
\hline
\end{tabular}

\footnotetext{
*Values were means \pm standard deviation from triplicate determinations.
}

\section{Conclusions}

The methods used in this study for gelatin and chitosan biopolymers allowed an optimization of the extraction yield and a determination of the optimal conditions necessary to obtain the best yield. Gelatin extracted from tilapia skins, has a maximum average extraction yield of $11.51 \%$ obtained by $0.20 \mathrm{M}$ acetic acid treatment, allowed an 
optimization of $+3 \%$ of the yield compared to the other acids used in this study, with interesting values of physicochemical properties such as viscosity, $\mathrm{pH}$, moisture and ash content, that range within the recommended grades for commercial gelatins. On the other hand, the chitosan obtained by the hydrothermal-chemical method has a maximum yield of $4 \%$, a degree of deacetylation of $67 \%$, allows the reduction of production costs and extraction time and can be an alternative to the classical techniques used. These findings could be used to help the fish and seafood industries to reuse and valorize the waste they generate and produce high value-added biopolymers in an economic, environmental and efficient manner. Furthermore, the use of fish gelatin and chitosan could be a potential alternative tool for innovative technologies to improve environmental quality and sustainability.

\section{Acknowledgements}

The authors thank CNRST (PPR/2015/10) for financial support.

\section{References}

[1] Département de la pêche maritime, Ministère de l'agriculture et de la pêche maritime, "Activités de valorisations du Secteur de l'industrie de la pêche," 2014.

[2] A. A. Karim and R. Bhat, "Fish gelatin: properties, challenges, and prospects as an alternative to mammalian gelatins," Food Hydrocoll., vol. 23, no. 3, pp. 563-576, May 2009.

[3] I. Hamed, F. Özogul, and J. M. Regenstein, "Industrial applications of crustacean by-products (chitin, chitosan, and chitooligosaccharides): A review," Trends Food Sci. Technol., vol. 48, pp. 40-50, Feb. 2016.

[4] M. Nouri, F. Khodaiyan, S. H. Razavi, and M. Mousavi, "Improvement of chitosan production from Persian Gulf shrimp waste by response surface methodology," Food Hydrocoll., vol. 59, pp. 50-58, Aug. 2016.

[5] B. Jamilah, K. W. Tan, M. R. Umi Hartina, and A. Azizah, "Gelatins from three cultured freshwater fish skins obtained by liming process," Food Hydrocoll., vol. 25, no. 5, pp. 1256-1260, Jul. 2011.

[6] A. Patria, "Production and characterization of Chitosan from shrimp shells waste," AACL Bioflux, vol. 6, no. 4, pp. 339-344, 2013.

[7] T. O. Truong, R. Hausler, F. Monette, and P. Niquette, "Valorisation des résidus industriels de pêches pour la transformation de chitosane par technique hydrothermo-chimique," Rev. Sci. Eau, vol. 20, no. 3, pp. 253-262, 2007.

[8] L. Niu, X. Zhou, C. Yuan, Y. Bai, K. Lai, F. Yang, Y. Huang, "Characterization of tilapia (Oreochromis niloticus) skin gelatin extracted with alkaline and different acid pretreatments," Food Hydrocoll., vol. 33, no. 2, pp. 336-341, Dec. 2013.

[9] W. Horwitz, Official methods of analysis of AOAC International. Gaithersburg, Md.: AOAC International, 2000.

[10] J. B. Dima, C. Sequeiros, and N. Zaritzky, "Chitosan from Marine Crustaceans: Production, Characterization and Applications," in Biological Activities and Application of Marine Polysaccharides, E. A. Shalaby, Ed. InTech, 2017.

[11] Naznin, Rokshana, "Extraction of Chitin and Chitosane from Shrimp (Metapenaeus monoceros) Shell by chemical method," Pak. J. Biol. Sci., vol. 8, no. 7, pp. 10511054, 2005.

[12] F. A. Ahing and N. Wid, "Extraction and Characterization of Chitosan from Shrimp Shell Waste in Sabah,” Trans. Sci. Technol., vol. 3, no. 1-2, pp. 227-237, 2016. 
[13] E. Szymańska and K. Winnicka, "Stability of Chitosan-A Challenge for Pharmaceutical and Biomedical Applications," Mar. Drugs, vol. 13, no. 4, pp. 1819-1846, Apr. 2015.

[14] K. Tokatlı and A. Demirdöven, "Optimization of chitin and chitosan production from shrimp wastes and characterization," J. Food Process. Preserv., p. e13494, Sep. 2017.

[15] S. Kumari, P. Rath, A. Sri Hari Kumar, and T. N. Tiwari, "Extraction and characterization of chitin and chitosan from fishery waste by chemical method," Environ. Technol. Innov., vol. 3, pp. 77-85, Apr. 2015.

[16] F. A. A. Sagheer, M. A. Al-Sughayer, S. Muslim, and M. Z. Elsabee, "Extraction and characterization of chitin and chitosan from marine sources in Arabian Gulf," Carbohydr. Polym., vol. 77, no. 2, pp. 410-419, Jun. 2009.

[17] M. N. R. Kumar, "A review of chitin and chitosan applications," React. Funct. Polym., vol. 46, no. 1, pp. 1-27, 2000.

[18] H. K. No and S. P. Meyers, "Preparation and Characterization of Chitin and Chitosan-A Review," J. Aquat. Food Prod. Technol., vol. 4, no. 2, pp. 27-52, Oct. 1995.

[19] P. Lertsutthiwong, N. C. How, S. Chandrkrachang, and W. F. Stevens, "Effect of Chemical Treatment on the Characteristics of Shrimp Chitosan.," J. Met. Mater. Miner., vol. 12, no. 1, pp. 11-18, 2002.

[20] A. Alishahi et al., "Enhancement and Characterization of Chitosan Extraction from the Wastes of Shrimp Packaging Plants," J. Polym. Environ., vol. 19, no. 3, pp. 776-783, Sep. 2011.

[21] B. Jamilah and K. G. Harvinder, "Properties of gelatins from skins of fish-black tilapia (Oreochromis mossambicus) and red tilapia (Oreochromis nilotica)," Food Chem., vol. 77, no. 1, pp. 81-84, 2002.

[22] M. Ahmad and S. Benjakul, "Characteristics of gelatin from the skin of unicorn leatherjacket (Aluterus monoceros) as influenced by acid pretreatment and extraction time," Food Hydrocoll., vol. 25, no. 3, pp. 381-388, May 2011.

[23] S. Zeng, X. Yan, W. Cao, P. Hong, C. Zhang, and L. Li, "Original article: Optimisation of extraction conditions and characteristics of skin gelatin from Nile tilapia (Oreochromis niloticus): Optimisation of extraction conditions and characteristics of skin gelatin,” Int. J. Food Sci. Technol., vol. 45, no. 9, pp. 18071813, Sep. 2010.

[24] S.-S. Choi and J. M. Regenstein, "Physicochemical and sensory characteristics of fish gelatin,” J. Food Sci., vol. 65, no. 2, pp. 194-199, 2000.

[25] A. da T. Alfaro, E. Balbinot, C. I. Weber, I. B. Tonial, and A. Machado-Lunkes, "Fish Gelatin: Characteristics, Functional Properties, Applications and Future Potentials," Food Eng. Rev., vol. 7, no. 1, pp. 33-44, Mar. 2015.

[26] P. Songchotikunpan, J. Tattiyakul, and P. Supaphol, "Extraction and electrospinning of gelatin from fish skin,” Int. J. Biol. Macromol., vol. 42, no. 3, pp. 247-255, Apr. 2008. 